\title{
Pineal-Thyroid Cytophysiological Responsiveness to Altered Steroid Hormone and Antihormone Milieu in the Rat (Rattus rattus)
}

\author{
Binu Rabindra Sinha \\ Ph.D. of Department of Zoology, Pineal Research Unit, University of Calcutta \\ 35, Ballygunge Circular Road, Kolkata 700019, India \\ Rupa Chattopadhyay \\ M.Sc. of Department of Zoology, Pineal Research Unit, University of Calcutta \\ 35, Ballygunge Circular Road, Kolkata 700019, India \\ Subrata Chakraborty (Corresponding author) \\ Professor, Pineal Research Unit, Department of Zoology, University of Calcutta \\ 35, Ballygunge Circular Road, Kolkata 700019, India \\ Tel: 91-9830-111-018Ｅ-mail: subratachakraborty2000@yahoo.co.in
}

\begin{abstract}
The current investigation was undertaken to assess the pineal and thyroid gland cytophysiology and function in response to an exogenously altered steroid milieu following administration of a steroid hormone and non-steroidal antihormones. In the present study male rats (Rattus rattus) were injected with estradiol at a dose of $2 \mathrm{mg}$, testosterone $100 \mu \mathrm{g}$, tamoxifen $100 \mu \mathrm{g}$ and flutamide $2 \mathrm{mg}$ per $100 \mathrm{~g}$ b.w. intramuscularly for 15 consecutive days. Control rats were similarly injected with peanut oil vehicle intramuscularly for the same duration as the treated groups. The results indicated that pineal and thyroid gland response to estradiol and testosterone administration was opposite in nature. Estradiol induced significant hypertrophy of pineal and thyroid cytophysiology as indexed from significantly increased pineal and thyroid karyomorphological and associated parameter values, testosterone contrarily caused significant atrophy of pineal and thyroid cytophysiological parameters. Tamoxifen acted as a true estrogen agonist, whereas flutamide showed an androgen antagonist nature, thereby causing hyperactivity of pineal and thyroid karyomorphological and associated functions similar to that observed in estradiol treated rats, but contrary to that shown by testosterone induction in these rats.
\end{abstract}

Keywords: Pineal, Thyroid, Karyomorphology, Sex-steroids, Non-steroidal antihormones

\section{Introduction}

Influence of endocrine modulation on pineal-thyroid responsiveness has long attracted the interest of endocrinologists. Amongst all, a diversely altered steroid milieu on the pineal-thyroid cell morphology and function following steroid hormones and antihormones administration appears to be controversial and inconclusive. Such responsiveness appears to depend on the dose and sex of the animal studied (Cardinali et al, 1987,1975; Nagle et al, 1974).

The influence of estradiol and androgen testosterone on pineal and thyroid responsiveness have been studied primarily using biochemical analyses and any composite study of cytomorphological changes employing these two glands awaits an in-depth investigation in mammals.

A number of reports indicate that steroid hormones can modulate pineal melatonin synthesis (Wallen \& Yochim, 1974; Cardinali \& Vacas, 1978). In this regard androgens and estrogens appear to have opposite roles in controlling melatonin synthesis and pineal function.

Findings indicate that sex steroids attaining the pinealocytes through systemic administration act as active modulators of pineal metabolic activity and change in the role of synthesis of pineal hormone in mammals (Clementi et al, 1965,1978; Karasek et al, 1976a,b; Hernandez et al, 1990). It was also later suggested that 
gonadal steroids modulate melatonin secretion by activating multiple receptors in the pineal gland including modulation of NAT (N-acetyl tranferase) (Luboshitzky et al, 1997; Okatani et al, 1997, 1998a,b).

In adult bandicoot rat, quantitative nuclear morphology and associated cytological observations indicate that exogenous estradiol is stimulatory, augmenting pineal cellular synthesis (Chakraborty et al, 1981). While estradiol treatment increased pinealocyte nuclear diameter in juvenile males, it had no effect on juvenile females. Estradiol exerted a dual effect of stimulation and inhibition, a sex specific action on the pineal gland of wild rat (Sahu \& Chakraborty, 1986).

It was reported that testosteone treatment decreased HIOMT (hydroxyindole-o-methyl transferase) activity in male rats (Houssay \& Barcelo, 1972b) and neonatal administration of testosterone also lowered HIOMT activity (Hyyppa et al, 1973). On the other hand, exogenously administrated testosterone was not stimulatory, if not inhibitory, to pinealocyte functions in male bandicoot rat (Chakraborty et al, 1981).

Influence of estrogen and testosterone on thyroid physiology and function is poorly documented. It was found that while testosterone facilitates mitogenic activity of the thyroid gland of rats, irrespective of sex and age, estradiol plays a gender specific stimulation of the thyroid gland (cf. Banu et al, 2001a). It was also observed that both testosterone and estradiol modify the proliferation of thyroid cancer cells (Banu et al, 2001b).

In rats estradiol induced suppression of thyroid function (D'Angelo, 1968; D'Angelo \& Fisher, 1969). It was reported earlier (Lampe \& Noack, 1962) that treatment of rats with testosterone propionate resulted in a diminished thyroidal uptake of radio iodine $\left(\mathrm{I}^{131}\right)$.

Other than steroid hormones used to study endocrinological aspects, a number of non-steroidal hormones that antagonize the action of a particular hormone have been developed. Studies have shown that non-steroidal antihormones like tamoxifen (an antiestrogen) and flutamide (an antiandrogen) have the capability to bind with sex steroid receptors present in the tissue. Tamoxifen acts as a pure antagonist at a low dose and a full agonist at higher doses (Rastogi \& Chieffi, 1975). Unlike in rats, tamoxifen administered to mice acts as a full estrogen agonist (Furr et al, 1979) and also induces atrophy of steroid sensitive glands (Harper \& Walpole, 1967).

Non-steroidal antihormones have the ability to bind with sex steroid receptors of the target organ. Consequently, it was envisioned that, the study of influence of these non-steroidal antihormones on steroid sensitive target organs (i.e. pineal and thyroid) using cell morphology and function studies, will aid to our understanding of their influence on these glands in male rats.

\section{Material and methods}

Adult male rats were used in the present investigation. The animals were acclimatized for three days prior to experimental use. Administrations of gonadal steroids and antihormones were followed as described.

\subsection{Control oil vehicle treatment}

Adult male rats $(\mathrm{N}=6)$ received $0.3 \mathrm{ml}$ of peanut oil vehicle daily during entire experimental schedule for fifteen days.

\subsection{Estradiol treatement}

Estradiol valerate (Progynon Depot, Schering AG, Germany) was diluted in peanut oil vehicle and administered to male adult rats $(\mathrm{N}=6)$ daily at a dose of $2 \mathrm{mg} / 100$ gm body weight (Chakraborty et al, 1981).

\subsection{Tamoxifen treatment}

Adult male rats $(\mathrm{N}=6)$ received antiestrogen tamoxifen (Tamoxifen citrate, Lyca Labs Ltd., India) daily in peanut oil vehicle at a dose of $500 \mu \mathrm{g} / 0.2 \mathrm{ml}$ oil per specimen (Rastogi \& Chieffi, 1975).

\subsection{Testosterone treatment}

Testosterone enanthate (Testosterone Depot, Schering AG, Germany) diluted in peanut oil vehicle was injected daily to each male adult, rat ( $\mathrm{N}=6)$ at a dose of $100 \mu \mathrm{g} / 100 \mathrm{gm}$ body weight (Chakraborty et al, 1981).

\subsection{Flutamide treatment}

Adult male rats $(\mathrm{N}=6)$ received flutamide (Flutide, Samarth Pharmaceuticals, India) in peanut oil vehicle daily at a dose of $2 \mathrm{mg} / 100 \mathrm{gm}$ body weight (Gromall et al, 1993).

All the injections were given intra-muscularly in alternate thigh muscle daily for fifteen consecutive days and the time of administration was between $14.00 \mathrm{~h}$ and $14.30 \mathrm{~h}$. The rats were housed in photoperiodic chambers fitted with fluorescent light and exhaust fan. The daily photoperiod 12L : 12D lights on at $06.00 \mathrm{Hrs}$. and off at 18.00 
Hrs. were controlled by timer switches (Surrey, U.K.). The rats were supplied with rat pellets and water ad libitum.

The experimental animals were maintained and used as per guidelines of Institutional Animal Ethics Committee, University of Calcutta accredited by Committee for the Purpose of Control and Supervision of Experiments on Animals (CPCSEA), Ministry of Environment and Forest, Govt. of India.

On the day of autopsy, i.e., on the sixteenth day of the experiment, the animals were killed by etherisation approximately $24 \mathrm{hrs}$ after the administration of last dose of the drug. Both the pineal and thyroid glands were excised out, fixed in Bouin's fixative and processed for routine histological studies.

\subsection{Histology}

Extensive studies have shown that in pineal and thyroid, an active phase, is characterized by increased nuclear size indicating stimulation of pineal and thyroid synthesis activity whereas inhibition of the pineal and thyroid is characterized by decreased nuclear size (Quay, 1965, 1976; Chakraborty \& Maiti, 1981; Chakraborty \& Maitra, 1982; Maiti \& Chakraborty, 1982; Diehl et al, 1984; Sahu \& Chakraborty, 1983, 1986; Chaudhuri \& Maiti, 1989; Hira et al, 1989; Peschke et al, 1989; Martinez Soriano et al, 1990; Chakraborty et al, 1981, 1982, 1992, 1994; Chakraborty, 1981, 1993, 1994; Chakraborty \& Sarkar, 1994; Ganguli et al, 1998, 2001; Bandopadhyay et al, 2000).

\subsection{Pineal karyomorphology}

In view of the foregoing observations, in the present study, the pineal gland activity had been mainly judged from karyometric values of the pineal parenchymal cells. Thus for morphometric evaluations at least 250 oval to round nuclei were measured from each of the five randomly selected midsaggital sections per specimen. In all cases, nuclei measured under oil immersion using 15 ocular x 100 objective lenses along with ocular micrometer scale. All the ocular diameter values were then converted to $\mu \mathrm{m}$ values. Individual values of the specimen were the mean figure of those five sectional measurements. The final mean values of the experimental groups were computed from these individual measurements (Chakraborty et al, 1981). No attempt was made to correct the data for possible shrinkage during preparation of the tissue (cf. Martinez Soriano et al, 1990).

\subsection{Numerical Density of Pinealocytes per microscopic field}

To determine the pinealocytes number (numeric density), per microscopic field, in every specimen five different areas were counted and means were calculated. In this way data was collected from six specimens from each of the control and treated groups (Shau \& Chakraborty, 1986).

\subsection{Thyroid karyomorphology and histomorphometry}

Histological investigations were carried out in the thyroid gland sections $(5 \mu \mathrm{m})$, which were stained using Iron-alum-haematoxylin and eosin.

In addition to histological observations the follicular diameter and the number of nuclei in the same follicle was noted. The ratio of the follicular diameter to the number of nuclei per follicle was evaluated and expressed as $\mathrm{D} / \mathrm{N}$ value. Additionally, morphometric data of epithelium percentage and cell height of the thyrofollicular cells were recorded. All ocular measurements were converted to $\mu \mathrm{m}$ (Chakraborty et al, 1992; Ganguli et al, 1998).

\subsection{Statistical Analysis}

Values were presented as the means of the observations of the experimental manipulations. All the karyomorpholgoical, karyodynamic and histomorphometric values for the control and treated rats were compared and the levels of significance were statistically evaluated by Student's ' $t$ ' test (Winer, 1971) and ANOVA (Microcal Origin, Version 4.00).

\section{Results}

\subsection{Histological Studies}

\subsubsection{Pineal gland}

Control oil vehicle treatment: Conventional staining of histological sections of the pineal gland reveal the gland as a solid homogenous parenchymatous mass, comprising of pinealocytes of various sizes, maximally with round to oval nuclei (Fig. 1).

Estradiol treatment: Estradiol injection in adult male rat produced a significant change in the glandular parenchyma, indicating hyperactivity of the gland. The cells showed secretory appearance as revealed by the appearance of pinealocyte nucleus containing single distinct nucleolus and less dense chromatin material (Fig. 2). 
The pinealocyte nuclei exhibited an increase in diameter $(p<0.001$, Fig. 11). This was supported by the significant decrease in numerical density of pinealocytes when compared to the numerical density observed in rat pinealocytes belonging to the control group $(\mathrm{p}<0.001$, Table 7A, Fig. 12).

Results from one-way ANOVA of pinealocyte nuclear diameters $[F(1,10)=662.5, p<0.01]$ and numerical density $[\mathrm{F}(1,10)=24.53, \mathrm{p}<0.01]$ in groups administered with oil vehicle (control) and estradiol reveal significant hypertrophied alterations of the estradiol treated groups compared with control mean values.

Tamoxifen treatment: Administration of tamoxifen evoked an estrogen agonist activity in the pineal. Histological observations revealed the presence of oval nuclei with prominent nucleolus and loose, indistinct chromatin materials (Fig 3). Such treatment manifested significant increase in nuclear diameter $(p<0.001$, Fig. 11). This was supported by the significant decrease in numerical density of pinealocytes when compared to the numerical density observed in rat pinealocytes belonging to the control group $(\mathrm{p}<0.001$, Table 7A, Fig. 12).

Results from one-way ANOVA of pinealocyte nuclear diameters $[\mathrm{F}(1,10)=606, \mathrm{p}<0.01]$ and numerical density $[\mathrm{F}(1,10)=36.50, \mathrm{p}<0.01]$ administered with oil vehicle (control) and tamoxifen reveal significant hypertrophy of the experimental values compared to the control groups.

Testosterone treatment: A significant atrophy of the pineal gland of adult male rat was observed following testosterone treatment. The pineal parenchyma exhibited oval nuclei with indistinct nucleolus and granular chromatin material (Fig 4). It induced a perceptible decrease in the nuclear size ( $p<0.001$, Fig. 11). This was supported by the significant increase in numerical density of pinealocytes when compared to the numerical density observed in rat pinealocytes belonging to the control group ( $p<0.001$, Fig. 12$)$.

Results from one-way ANOVA of pinealocyte nuclear diameters $[\mathrm{F}(1,10)=36.15, \mathrm{p}<0.01]$ and numerical density $[\mathrm{F}(1,10)=52.76, \mathrm{p}<0.01]$ in groups administered with oil vehicle (control) and testosterone reveal significant hypotrophy of the experimental values compared to the control groups.

Flutamide treatment: Antiandrogen, flutamide acted as true androgen antagonist, inducing hyperactivity of the pineal gland. The pinealocyte nuclei showed the presence of a prominent nucleolus and loose chromatin material (Fig. 5). This alteration in the glandular activity was evident from the increase nuclear diameter ( $<<0.05$, Fig. 11). This was supported by the significant decrease in numerical density of pinealocytes when compared to the numerical density observed in rat pinealocytes belonging to the control group $(\mathrm{p}<0.001$, Fig. 12).

Results from one-way ANOVA of pinealocyte nuclear diameters $[\mathrm{F}(1,10)=124.5, \mathrm{p}<0.01]$ and numerical density $[\mathrm{F}(1,10)=57.17, \mathrm{p}<0.01]$ in groups administered with oil vehicle (control) and flutamide reveal significant differences in the mean values and thus indicating significant hypertrophied changes of the flutamide treated groups compared with control mean values.

\subsubsection{Thyroid Gland}

Oil vehicle treatment (control): The thyroid histology of the adult control male rats reveals follicles formed by simple epithelium whose follicular radius was seen to be normal. The follicles were regular in size and shape and lumina filled with homogenous colloid. (Fig. 6).

Estradiol treatment: Estradiol treatment induced stimulation of thyroid gland when compared to the follicles of control rats (Fig. 7). The diameters of epithelial cells were significantly greater than the epithelial cells of the control ( $p<0.001$, Fig. 13). Though there was no significant change in the thyrofollicular diameter of estradiol treated rats. The collected data also exhibit a significant increase in epithelium height of thyroid follicles in the treated rats $(\mathrm{p}<0.01$, Fig. 14$)$. The $\mathrm{D} / \mathrm{N}$ value was also significantly greater when compared to those of control rats ( $<<0.01$, Fig. 15).

Analysis of variance (one-way) for thyroid nuclear diameter $[\mathrm{F}(1,10)=90, \mathrm{p}<0.01]$, epithelium height $[\mathrm{F}(1,10)$ $=6.79, \mathrm{p}<0.05]$ and $\mathrm{D} / \mathrm{N}[\mathrm{F}(1,10)=10, \mathrm{p}<0.05]$ of the thyroid gland from control and treated animals reveal significant hypertrophied alterations of the estradiol treated groups compared with control mean values.

Tamoxifen treatment: Tamoxifen treatment induced stimulation of thyroid gland when compred to the follicles of control rats (Fig. 8). The diameters of epithelial cells were significantly greater than the epithelial cells of the control $(\mathrm{p}<0.001$, Fig. 13). However, there was no significant change in the thyrofollicular diameter of tamoxifen treated rats. The collected data also exhibit a slightly significant decrease in epithelium height of thyroid follicles in the treated rats $(\mathrm{p}<0.025$, Fig. 14). The $\mathrm{D} / \mathrm{N}$ value was also significantly greater when compared to that of control rats ( $\mathrm{p}<0.001$, Fig. 15).

Analysis of variance (one-way) for thyroid nuclear diameter [F $(1,10)=92.5, \mathrm{p}<0.01]$, epithelium height $[\mathrm{F}$ $(1,10)=5.29, \mathrm{p}<0.05]$ and $\mathrm{D} / \mathrm{N}[\mathrm{F}(1,10)=5.60, \mathrm{p}<0.05]$ of the thyroid gland from control and treated animals 
reveal significant hypertrophied alterations of the testosterone treated groups compared with control mean values.

Testosterone treatment: Testosterone treatment induced inhibition of the thyroid gland when compared to the follicles of the control rats (Fig. 9). The diameters of epithelial cells were significantly less than the epithelial cells of the control ( $p<0.025$, Fig. 13), though there was no significant change in the thyrofollicular diameter of treated rats. The epithelium height of thyroid follicles in the treated rats showed slightly significant decrease $(p<0.005$, Fig. 14). The $\mathrm{D} / \mathrm{N}$ value was significantly lower when compared to that of the control rats $(\mathrm{p}<0.005$, Fig. 15).

Analysis of variance (one-way) for thyroid nuclear diameter $[\mathrm{F}(1,10)=5.73, \mathrm{p}<0.05]$, epithelium height $[\mathrm{F}$ $(1,10)=10.11, \mathrm{p}<0.01]$ and $\mathrm{D} / \mathrm{N}[\mathrm{F}(1,10)=9.85, \mathrm{p}<0.05]$ of the thyroid gland from control and treated animals reveal significant hypotrophied alterations of the testosterone treated groups compared with control mean values.

Flutamide treatment: Flutamide treatment induced stimulation of thyroid gland when compared to the follicles of control rats (Fig. 10). The diameters of epithelial cells were significantly greater than the epithelial cells of the control ( $p<0.005$, Fig. 13), although there was no significant change in the thyrofollicular diameter of flutamide treated rats. There is a significant change in epithelium height of thyroid follicles in the treated rats $(\mathrm{p}<0.01$,Fig. 14). The $\mathrm{D} / \mathrm{N}$ values also showed significant change when compared to those of control rats $(\mathrm{p}<0.01$, Fig. 15$)$.

Analysis of variance (one-way) for thyroid nuclear diameter [F $(1,10)=70, p<0.01]$ of the thyroid gland from control and treated animals reveal significant hypertrophied epithelial cell alterations only in flutamide treated groups compared with control mean values.

\section{Discussion}

The current quantitative morphology as evident from karyometric values and associated histological studies indicate that both pineal and thyroid cytology show differential response to altered steroid milieu, induced by exogenous administration of sex steroids and non-steroidal antihormones.

It is interesting to note that the cytophysiological changes indicated by karyomorphological alterations in the pineal gland (Quay, 1965, 1976; Chakraborty et al, 1981; Diehl et al, 1984; Sahu \& Chakraborty, 1983, 1986; Hira et al, 1989; Peschke et al, 1989; Martinez Soriano et al, 1990) and thyroid (Chakraborty et al, 1992; Ganguli et al, 1998) in mammals provide inextricable indices of the nature of activities of these glands.

Evidence reveals that the pineal gland influences the gonadal activities and that a reciprocal effect of the gonads on the pineal function also exists (Wurtman et al, 1965), indicating that the pineal acts as a target organ for the sex steroids (Cardinali et al, 1975). Both estrogen and testosterone are taken up by the pineal gland and metabolized within the pinealocytes (Nagle et al, 1972; Cardinali et al, 1974b) which in return influences the biosynthetic pathway of the gland.

The pineal gland reacts to estradiol input by becoming significantly hyperactive, in so far as the synthetic phase of the pineal parenchymal cells are concerned. This is evident from the augmented pinealocyte nuclear size and the decrease in cell numerical density. Conversely, exogenously administered testosterone initiated the inhibition of the cellular synthetic process in the gland, indicated by reduced nuclear diameter and the increase in numerical density of pinealocytes in an area (Fig. 4, Fig. 11).

It is apparent from the present study that pineal cellular response to estradiol and testosterone in adult male rats are the inverse of each other. The current observations are supported by studies that show exogenous estradiol induces hyperactivity of the pineal gland (Clementi et al, 1965) and thereby result in the stimulation of the pineal synthetic process in both adult male (Chakraborty et al, 1981) and juvenile rats (Sahu \& Chakraborty, 1986). This hormone also induced mitosis in pinealocytes of juvenile rats (Sahu \& Chakraborty, 1986).

Biochemical analysis, authenticating the histological findings reveals that the female sex steroids augmented the pineal content of DNA, RNA and proteins in mammals (Nir et al, 1970). Similarly, in vitro studies with rat pineal gland indicate that estradiol significantly enhances the HIOMT levels (Mizobe \& Furokawa, 1976), the enzyme required for the melatonin synthesis. Other in vivo and in vitro experiments also show that estradiol augments the melatonin synthesis resulting in an increase in pineal melatonin content in both rats and guinea pigs (Cardinali et al, 1987). However, in contrast, recent publications suggest that estrogen modulates both nocturnal pineal melatonin synthesis and adenylate cyclase activity in peripubertal female rats, indicating inhibition of the pineal gland (Okatani et al, 1997, 1998a, b). 
Male sex hormone androgen induces inhibition of the pineal cellular synthetic activity in hamsters (Armer, 1976) while it is non-stimulatory to pineal gland function in wild male rats (Chakraborty et al, 1981). In vitro experiments in rats reveal that testosterone reduces the serotonin (Walker and Timiras, 1980) and melatonin content of the pineal gland (Cardinali et al, 1987) thus supporting the present results which imply that the male sex steroids act as an inhibitor of the pineal gland activity.

From these studies it was evident that the sex steroids attaining the pinealocytes through systemic circulation act as an active modulator of pineal metabolic function and thereby alter the rate of synthesis of melatonin in mammals (Clementi et al, 1965; Karasek et al, 1976a,b; Cardinali \& Vacas, 1978; Hernandez et al, 1990).

However, disparity of action of sex hormones on pineal gland exists, indicating that exogenously administered sex steroid hormones have a dose dependent effect on this gland (Preslock, 1977). These are evident from experiments with female rats where HIOMT activity is either enhanced (Houssay \& Barcelo, 1972a) or depressed (Wurtman et al, 1965) by lower or higher dose of estrogen respectively. Similarly, large dose of androgen inhibit HIOMT activity (Nagle et al, 1974; Cardinali, 1981) while small doses of this hormone augment the enzyme activity (Cardinali et al, 1975; Cardinali, 1981).

Our present results corroborate with earlier suggestion that the pineal gland acts as the target organ for both estrogen and testosteone in mammals (Cardinali et al, 1975). Furthermore, this gland is believed to be functionally interrelated-gonadal endocrine system (Kitay \& Altschule, 1954; Thieblot \& Le Bar, 1955).

Besides influencing the pineal gland, the physiology of the sex and reproduction are intimately related with the thyroid synthetic and secretory activities, thus corroborating the thyroid-gonadal interrelationship in mammals.

The present investigation gives an insight into the changes brought about separately by estradiol and testosterone treatment on the thyrofollicular cell morphology in adult male rats. It was observed that exogenous estradiol had a stimulatory effect on the thyroidal activity as reflected by the significant increase in the size of the epithelial nuclei leading to a significant increase in thyroid nuclear diameter values. This was supported by the increased epithelium height when compared to the controls. With the increase in size of epithelial nuclei a reduction in their number was also observed. Hence an increase in the ratio of follicular diameter to the number of nuclei present in these follicles corroborated augmentation of thyrofollicular activity (Chakraborty et al, 1992; Banu et al, 2001a) induced by the estradiol treatment.

Contrarily, epithelial nuclear size showed a significant decrease in testosterone treated rats supported by a significant decrease in epithelial height. With the decrease in size of epithelial nuclei there was an increase in their number all around the epithelium lining the follicular lumen. Hence a decrease in the ratio of follicular diameter to the number of nuclei present in these follicles corroborated suppression of thyrofollicular activity (Chakraborty et al, 1992) induced by testosterone treatment. However there is not much information on the effects of sex steroids on the normal development and growth of the thyroid. Studies conducted to examine the effect of sex steroids on thyroid growth have indicated that in rats testosterone facilitates the mitogenic activity of the thyroid gland irrespective of sex and age while estradiol plays a gender-specific stimulatory role on the thyroid gland (cf. Banu et al, 200a).

Other than the gonadal steroids, several non-steroidal antihormones, like tamoxifen (antiestrogen) and flutamide (antiandrogen), have been developed that possess the capacity to antagonize normal steroid activity (Rastogi \& Cieffi, 1975).

The present studies conducted in adult male rats have shown that non-steroidal antiestrogen and tamoxifen induce significant hypertrophy of pineal gland as indicated by the increased pinealocyte nuclear size, and decrease in the number of pinealocytes in an area. Also, there was stimulation of the thyroid, which was supported by the significantly increased nuclear diameter of the cells in the epithelium lining the follicle, accompanied by the increased $\mathrm{D} / \mathrm{N}$ value when compared to the control group.

The hyperactivity of both pineal and thyroid glands induced by tamoxifen is similar to the results obtained following estradiol administration in adult male rats. This estrogen agonist activity of tamoxifen is supported by earlier reports where tamoxifen administration produced results similar to estrogen treatment (Rastogi \& Chieff, 1975). Investigators believe that tamoxifen shares with other antiestrogen the property of stimulating early estrogen responses and only later antagonizing normal estrogen action. It also shares the property of binding cytoplasmic estrogen receptor and inducing its translocation into cell nuclei. Since this parallels the action of estradiol itself, it may be supposed that the early estragenicity of tamoxifen and other anti-estrogens results from this action (Clark et al, 1973, 1974; Ruh \& Ruh, 1974; Katzenellenbogen \& Ferguson, 1975; Cidlowski \& Muldoon, 1976; cf. Koseki et al, 1977). 
Similarly, non-steroidal antihormone, flutamide, used in the present experimental study, enhances the pinealocyte nuclear size, leading to hyperactivation of the pineal gland. This experimental observation is supported by a study showing that three weeks after administration of antiandrogens, like cyproterone and cyproterone acetate, to adult male rats, the light cells of the pineal gland were hyperactive and hypertrophied with enlarged nucleoli, increased number of ribosomes and mitochondria, enlarged endoplasmic reticulum and Golgi apparatus (Gusek, 1971, 1976).

Simultaneously, exogenous flutamide seemed to stimulate thyroidal function. This is reflected by the occurrence of increased nuclear diameter of the cells in the epithelium lining the follicles. Accompanied by the increased $\mathrm{D} / \mathrm{N}$ value when compared to the control group, flutamide (an antiandrogen) causes reduction in the weight of the androgen dependent organs, such as epididymis and seminal vesicle in treated groups. Since these non-steroidal antihormones have the capability to bind with sex steroid receptors of the target organ and alter its activity, it may be possible that these anti-hormones may also bind to receptors present in other sex steroid sensitive glands, e.g. pineal and thyroid, thereby modulating the morphology and function of these glands.

From our elaborate investigation it may be summarized that estradiol and testosterone show antagonistic influence of pineal-thyroid cytophysiology. Whereas estradiol is stimulatory to the pineal-thyroid cell functional activities, testosterone is inhibitory to the pineal-thyroid cell morphology and function. Our present investigation provides first time evidence of the influence of these non-steroidal antihormones on pineal and thyroid cytophysiology and puts forth the idea that, at the employed dose and duration, both tamoxifen and flutamide were also responsible for stimulatory cytophysiology of both the pineal and thyroid gland in the male rat.

\section{Acknowledgement}

The authors wish to thank Profesor A.K. DuttaGupta for providing photomicrographic facilities.

\section{References}

Armer, A. A. (1976). The effects of castration and testosterone of the fine structure of hamster pinealocytes. Anat. Rec., 184, 346 (Abstract).

Bandyopadhyay, R, S. Ganguli, S. Chakraborty. (2000). Inverse changes in the pineal and adrenocortical morphology induced by dehydration stress was independent of extreme long and short daily photoperiod in neonatal chicks (Gallus domesticus). Proc. Zool. Soc. 53, 4-14.

Banu, S. K., J. A. Arosh, P. Govindarajulu, M. M. Aruldhas. (2001a). Testosterone and estradiol differentially regulate thyroid growth in Wistar rats from immature to adult age. Endocr. Res., 27, 447-463.

Banu, S. K., J. A. Arosh, P. Govindarajulu, M. M. Aruldhas. (2001b). Testosterone and estradiol have specific modulatory effect on the proliferation of human thyroid papillary and follicular carcinoma cell lines independent of TSH action. Endocrine Pathology, 12, 315-327.

Cardinali, D. P., C. A. Nagle, J. M. Rosner. (1974b). Metabolic fate of androgens in the pineal organ: uptake binding to cytoplasmic proteins and conversion of testosterone into $5 \alpha$-reductase metabolites. Endocrinology, 95, 179-187.

Cardinali, D. P., C. A. Nagle, J. M. Rosner. (1975). Gonadal steroids as modulators of the function of the pineal gland. Gen. Comp. Endocrinol., 26, 50-58.

Cardinali, D. P. (1977). Nuclear receptor estrogen complex in the pineal gland. Modulation by sympathetic nerves. Neuroendocrinology, 24, 336-346.

Cardinali, D. P., M. I. Vacas, (1978). Feedback control of pineal function by reproductive hormones - a neuroendocrine paradigm. J. Neural. Transm. Suppl., 13, 175-201.

Cardinali, D. P., M. I. Vacas, P. V. Gejman. (1981). The sympathetic superior cervical ganglia as peripheral neuroendoceine centers. J. Neural. Transm., 52, 1-12.

Cardinali, D. P., M. I. Vacas, M. I. Keller-Sarmiento, G. S. Etchegoyen, E. N. Pereyra, H. E. Chuluyan. (1987). Neuroendocrine integrative mechanisms in mammalian pineal gland: effects of steroid and adenohypophysial hormones on melatonin synthesis in vitro. J. Steroid Biochem., 27, 565-571.

Chakraborty, S. (1981). Cytology of pineal gland and its response to epinephrine and 6-hydroxydopanine in Indian weaver bird (Ploceus philippinus). Mikroskopie, 38, 187-192.

Chakraborty, S. (1993). A comparative study of annual changes in pineal gland morphology with reference to the influence of melatonin on testicular activity in Tropical birds, Psittacula cyanocephala and Ploceus philippinus. Gen. Comp. Endocrinol., 92, 71-79. 
Chakraborty, S. (1994). Exogenous melatonin act as a reproductive phase dependent modulator of the relationship in morphology between pineal and adrenal cortex in male Blossom headed parakeet (Psittacula cyanocephala) and Indian weaver bird (Ploceus philippinus). Biol, Rhythm, Res, 25, 121-132.

Chakraborty, S., B. R. Maiti. (1981). Influence of prolactin on pineal gland activity in chicks. Gen. Comp. Endocrinol., 44, 226-229.

Chakraborty, S., S. Maitra. (1982). Stress factors can reverse the pinealostimulatory effects of 6-hydroxydopanine on the pineal gland of Blossom headed parakeet (Psittacula cyanocephala). Zbl. Vet. Med. C. Anat. Histol. Embryol, 11, 117-123.

Chakraborty, S., A. Sarkar. (1994). Seasonal changes in pineal gland response to exogenous testosterone in the male Blossom headed parakeet (Psittacula cyanocephala) and Indian weaver bird (Ploceus philippinus). Folia biologica (Krakow), 42, 49-55.

Chakraborty, S., A. Sahu, A. Ghosh. (1981). Cellular responses of the pineal gland to sex steroids in Bandicoot rat. Mikroskopie, 38, 256-261.

Chakraborty, S., P. R. Ghosh, B. R. Maiti. (1982). Cytophysiological responses of the pineal gland to intermale aggression in a wild rat. Endokrinologie, 80, 353-856.

Chakraborty, S., S. Chattapadhyay, A. Sarkar, R. Bandyopadhyay. (1992). Melatonin induced morphology of the thyrofollicular activity in Blossomheaded Parakeets (Psittacula cyanocephala) and Indian Weaver birds (Ploceus philippinus). Eur. Arch. Biol., 103, 245-299.

Chakraborty, S., S. Chattapadhyay, R. Bandyopadhyay. (1994). Testosterone and prolactin effects on pinealocytes nuclei from migratory Red headed bunting - comparison with testicular weight. Eur. Arch. Biol., $105,13-17$.

Chaudhuri, S., B. R. Maiti. (1989). Pineal activity during the seasonal gonadal cycle in a wild avian species, the Tree pie (Dendrocitta vagabunda). Gen. Comp. Endocrinol., 76, 346-349.

Cidlowski, J. A., T. G. Muldoon. (1976). Dissimilar effect of antiestrogens upon estrogen receptors in responsive tissues of male and female rats. Biol. Reprod., 15, 381.

Clark, J. H., J. N. Anderson, E. J. Peck Jr. (1973). Estrogen receptor-antiandrogen complex : Atypical binding by uterine nuclei and effects on uterine growth. Steroids, 22, 707.

Clark, J. H., J. N. Anderson, E. J. Peck Jr. (1974). Oestrogen receptors and antagonism of steroid hormone action. Nature, 251, 446.

Clementi, R., F. Fraschini, E. Miller, A. Zanoboni. (1965). The pineal gland and the control of electrolyte balance and of gonadotrophic secretion : functional and morphological observations. Progr. Brain Res., 10, 585-603.

D'Angelo, S. A. (1968). Simultaneous effects of estradiol on TSH secretion and adrenocortical function in male and female rats. Endocrinology, 82, 1035-1041.

D'Angelo, S. A., J. S. Fisher. (1969). Influence of estrogen on pituitary thyroid system of female rat : Mechanisms and loci of action. Endocrinology, 84, 117-121.

Diehl, B. J. M., U. Heidbuchel, H. A. Welker, I. Vollrath. (1984). Day / night changes of pineal gland volume and pinealocyte nuclear size assessed for consecutive days. J. Neural. Transm, 60, 19-29.

Furr, B. J. A., J. S. Patterson, D. Richardson, S. R. Slater, A. E. Wakeling. (1979). In Pharmacological and Biochemical properties of drug substances (Ed. Goldberg ME) Vol 2, pp 355-399, Washington, APA.

Ganguli, S., R. Banerjee, S. Chakraborty. (1998). Disparate action of estrogen on the pineal and the thyroid gland of neonatal chicks (Gallus domesticus). Proc. Zool. Soc. Calcutta, 51, 92-100.

Gromoll, J., G. F. Weinbaur, M. Simoni, E. Nieschlag. (1993). Effects of antiandrogen and ethane dimethylsulphonate (EDS) on gene expression, free subunits, bioactivity and secretion of pituitary gonadotrophins in male rats. Mol. Cell Endocrinol, 91, 119-125.

Gusek, W. (1971). The influence of an antiandrogen (cyproterone acetate) on the morphology of the pineal body. Acta. Endocrinol. (Kbh.) (Suppl.), 152, 37.

Gusek, W. (1976). Die fienstructur der rattenzirbel und ihr nerhatten untereinfluss von antiandrogen und mach kastration. Endokrinologie, 67, 129-151. 
Harper, M. J. K., A. L. Walpole. (1967). A new derivative of triphenylethylene : effect on implantation and mode of action in rats. J. Reprod.. Fert, 13, 109-119.

Hernandez, G., P. Abreu, R. Alonso, C. Santana, F. Moujir, C. H. Calzadilla. (1990). Castration reduces the nocturnal rise of melatonin levels in the male rat by implanting its noradrenergic input. J. Neuroendocrinol., 2, 777-782.

Hira, Y., Y. Sakai, S. Matsushima. (1989). Comparisons of sizes of pinealocytes nuclei, and pinealocytes in young and adult Chinese hamsters (Cricetulus griseus) under different photoperiod conditions. J. Pineal. Res., 7 , 411-418.

Houssay, A. B., A. C. Barcelo. (1972b). Effects of testosterone upon the biosynthesis of melatonin by pineal gland. Acta. Phyiol. (Latino-Amer), 22, 274-275.

Hyyppa, M. T., D. P. Cardinali, R. J. Wurtman. (1973). Sex dependent increase in pineal hydroxyindole-o-methyltransferase activity after a single intraventricular injection of 6-hydroxydopamine to newborn rats. Neuroendocrinology, 11, 274-283.

Karasek, M., M. Rawlikowski, J. A. Kappers, H. Stepien. (1976a). Influence of castration followed by administration of LH-RH on the ultrastructure of rat pinealocytes. Cell Tissue Res., 167, 325-339.

Karasek, M., M. Rawlikowski, P. Pevet, H. Stepien. (1976b). Ultrastructural and fluorescence histochemical studies of rat pineal gland after castration. Ann. Med. Sect. Pol. Acad. Sci., 21, 1-2.

Katzenellenbogen, B.S., E. R. Ferguson. (1975). Antiestrogen action in the uterus : Biological ineffectiveness of nuclear bound estradiol after antiestrogen. Endocrinology, 11, 274-283.

Kitay, J. I., M. D. Altschule. (1954). The pineal gland, a review of the physiologic literature. Harvard Univ Press, Cambridge.

Koseki, Y., T. Z. David, G. C. Chamnees, W. L. Mc Guire. (1977). Estrogen receptor translocation and replenishment by the antiestrogen tamoxifen. Endocrinology, 101, 1104.

Lampe, C. F. J., E. L. Noach. (1962). Acta. Physiol. Pharmacol. Neerl., 11, 466.

Luboshitzky, R., M. Dharan, D. Goldman, P. Herer, Y. Hiss, P. Lavie. (1997). Seasonal variation of gonadotrophins and gonadal steroid receptors in human pineal gland. Brain Res. Bull, 44, 665-670.

Maitra, S. K., S. Chakraborty. (1983). Impact of sympatholytic drug (6-OH DA) on osmotic stress induced changes in adrenocorticomedullary system of blossom headed parakeet (Psittacula cyanocephala). Arch. Biol. (Bruxelles), 94, 385-398.

Mizobe, F., M. Furokawa. (1976). Enhancement of hydroxyindole-o-methyl-transferase and DNA dependent RNA polymerase activities induced by estradiol in rat pineals in culture. Eur. J. Biochem, 66, 193-199.

Nagle, C. A., D. P. Cardinali, J. M. Rosner. (1974). Effects of castration and testosterone administration on pineal and retinal hydroxyindole-o-methyl transferases of male rats. Neuroendocrinology, 14, 14-23.

Nagle, C. A., N. R. Neuspiller, D. P. Cardinali, J. M. Rosner. (1972). Uptake and effect of 17ß-estradiol on pineal hydroxyindole-o-methyltransferase (HIOMT) activity. Life Sci., 12, 1109-1116.

Okatani. Y., K. Hayashi, K. Watanabe, N. Morioka, Y. Sagara. (1998a). Effect of estrogen on melatonin synthesis in female peripubertal rats as related to adenylate cyclase activity. J. Pineal Res., 25, 245-250.

Okatani, Y., K. Hayashi, K. Watanabe, N. Morioka, Y. Sagara. (1998b). Effect of estrogen on melatonin synthesis in female peripubertal rats. J. Pineal Res., 24, 67-72.

Okatani. Y., K. Watanabe, N. Morioka, K. Hayashi, Y. Sagara. (1997). Nocturnal changes in pineal melatonin synthesis during puberty : relation to estrogen and progesterone levels in female rats. J. Pineal Res., 22, 33-41.

Peschke, E., M. Schon, S. Tertsch, D. Peschke, J. Peil. (1989). Morphometric investigations of the pineal gland after ganglionectony and thyroidectomy under the aspect of circadian and seasonal variation. J. Hirnforsch, 30, 399-407.

Preslock, J. P. (1977). Gonadal steroid regulation of pineal melatonin synthesis. Life Sci., 20, 1299-1304.

Quay, W. B. (1965). Histological structure and cytology of the pineal organ in birds and mammals. In Structure and function of epiphysis cerebri (Eds. Kappers J.A, Schade JP), pp 49-86, Elsevier: Amsterdam.

Quay, W. B. (1976). Seasonal cycle and physiologic correlates of pinealocyte nuclear and nucleolar diameters in the bats, Myotis lucifugus and Myotis sodalis. Gen. Comp. Endocrinol, 29, 369-375. 
Rastogi, R. K., G. Chieffi. (1975). The effects of antiandrogens and antiestrogens in nonmammalian vertebrates. Gen. Comp. Endocrinol, 26, 79-91.

Ruh, T. S., M. F. Ruh. (1974). The effect of antiestrogens on the nuclear binding of the estrogen receptor. Steroids, 24, 209.

Sahu, A., S. Chakraborty. (1983). Pineal cytology during estrouscycle of wild Bandicoot rat, Bandicota bengalensis. Arch. Biol. (Bruxelles), 94, 399-411.

Sahu, A., S. Chakraborty. (1986). Estradiol modulation of pineal gland activity in the wild bandicoot rat, Bandicota bengalensis. Acta. Anat., 125, 1-5.

Thieblot, L., Le Bars. (1955). La glande pineale ou epiphyse. Anatomie-Histologie-Physiologie-Clinique, Librairie Malonie, Paris.

Walker, R. F., P. S. Timiras. (1980). Loss of serotonin circadian rhythms in the pineal gland of androgenized female rats. Neuroendocrinology, 31, 265-269.

Wallen, E. P., J. M. Yochim. (1974). Rhythmic function of pineal hydroxyindole-o-methyltransferase during the estrous cycle : an analysis. Biol. Reprod., 10, 461-466.

Wurtman, R. J., J. Axelrod, S. H. Synder, E. W. Chu. (1965). Changes in the enzymatic synthesis of melatonin in the pineal gland during the estrous cycle. Endocrinology, 76, 798-800.

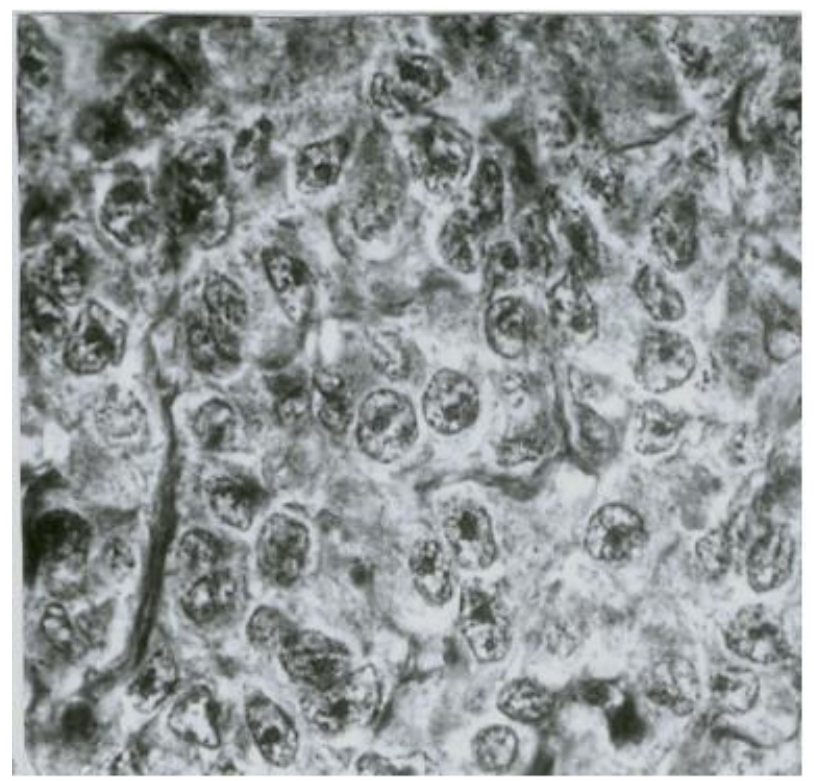

Figure 1. Microphotograph of pineal gland section from control adult male rat showing normal nuclear diameter and cell density. $x 320$ 


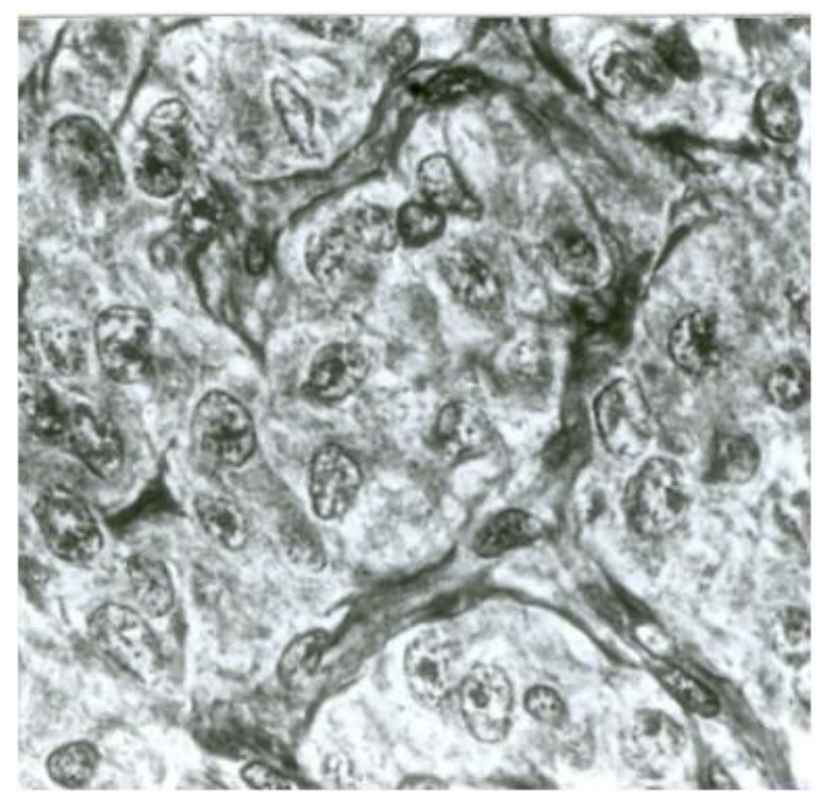

Figure 2. Microphotograph of pineal gland section from estradiol treated adult male rat showing increased nuclear diameter and decreased cell density. x320

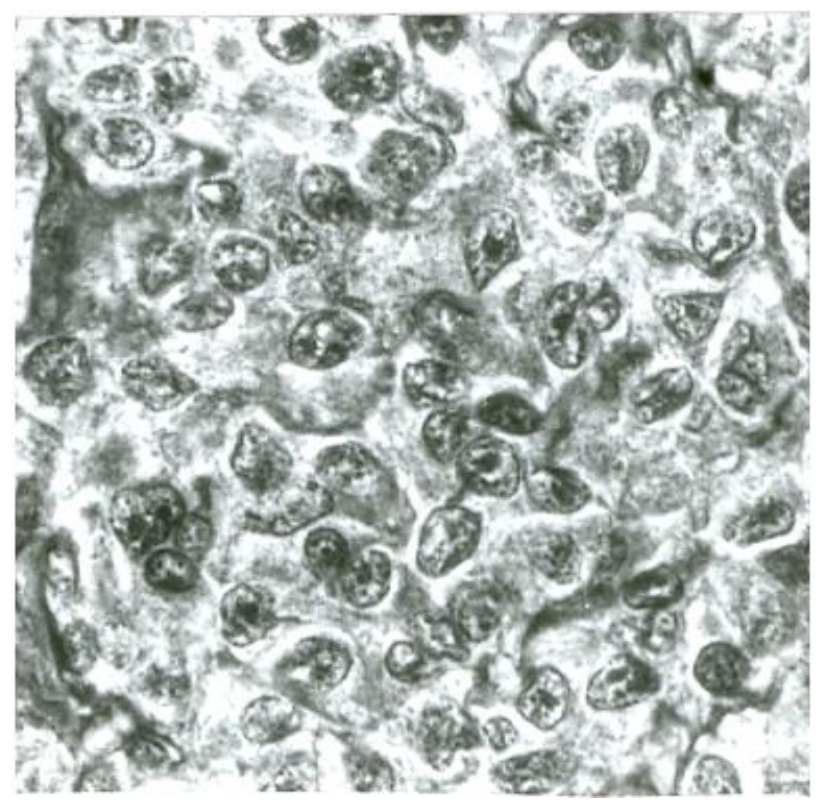

Figure 3. Microphotograph of pineal gland section from tamoxifen treated adult male rat showing increased nuclear diameter and decreased cell density. x320 


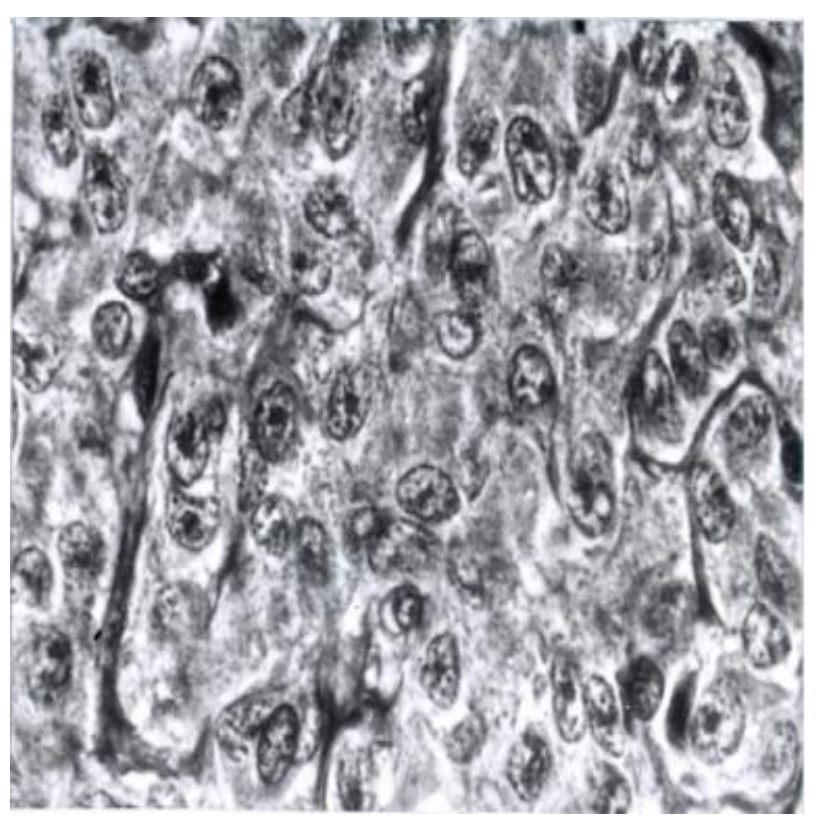

Figure 4. Microphotograph of pineal gland section from testosterone treated adult male rat showing decreased nuclear diameter and increased cell density. x320

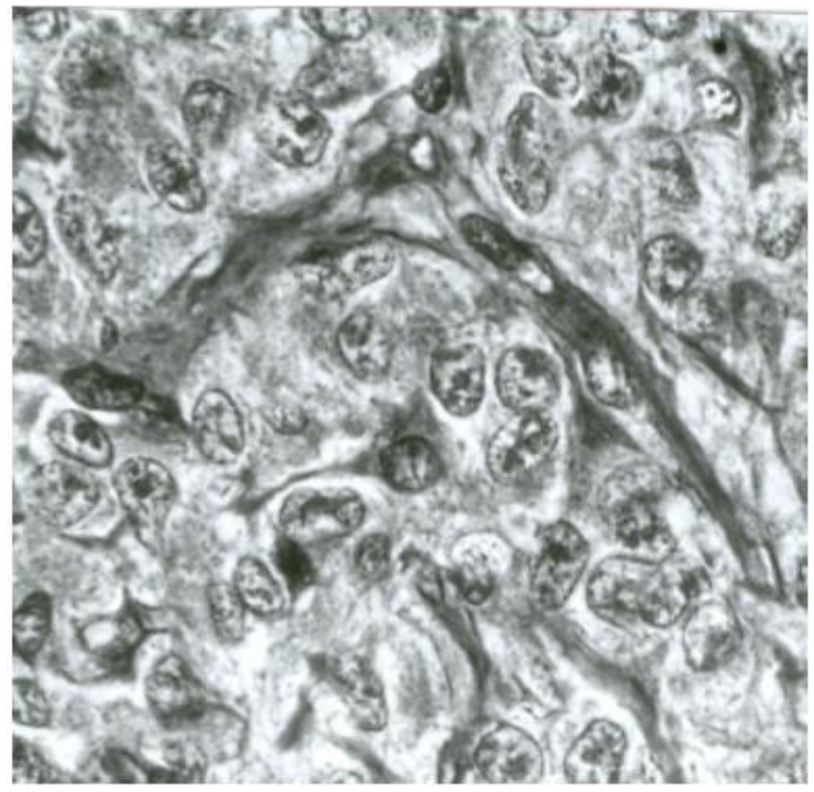

Figure 5. Microphotograph of pineal gland section from flutamide treated adult male rat showing increased nuclear diameter and decreased cell density. x320 


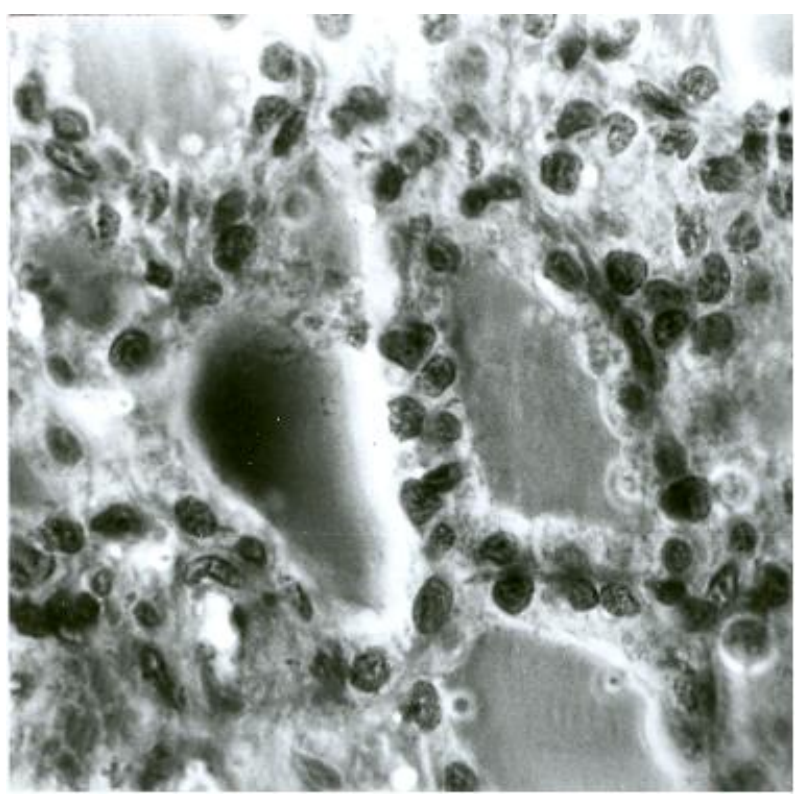

Figure 6. Microphotograph of thyroid gland section from control adult male rat showing normal nuclear diameter, epithelium height and follicular diameter. x320

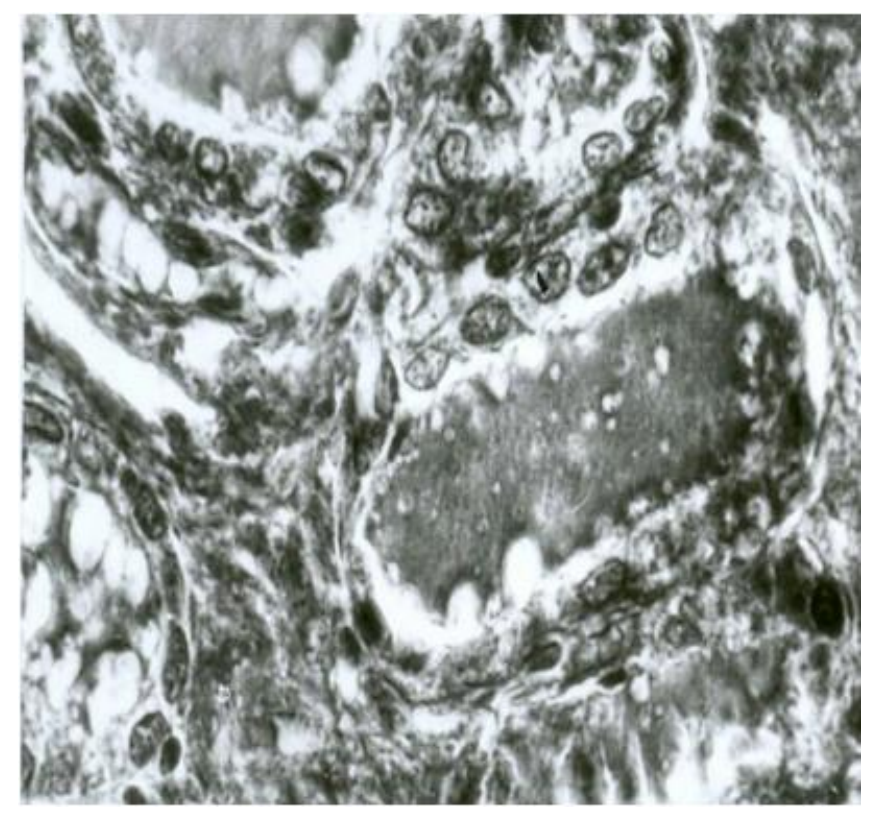

Figure 7. Microphotograph of thyroid gland section from estradiol treated adult male rat showing increased nuclear diameter and increased epithelium height. Note the vacuolated colloid. x320 


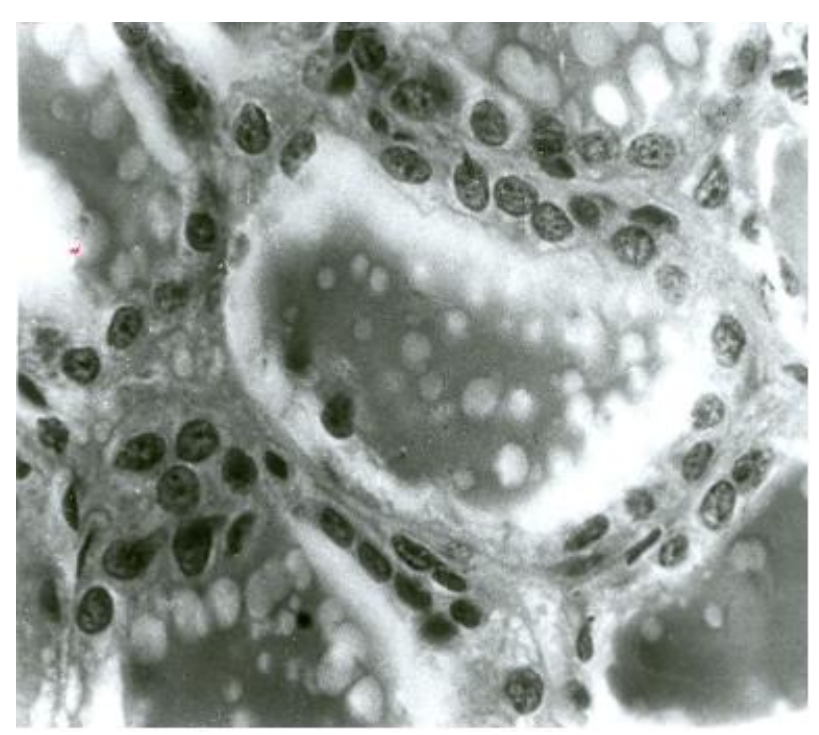

Figure 8. Microphotograph of thyroid gland section from tamoxifen treated adult male rat showing increased nuclear diameter and increased epithelium height. Note the vacuolated colloid. x320

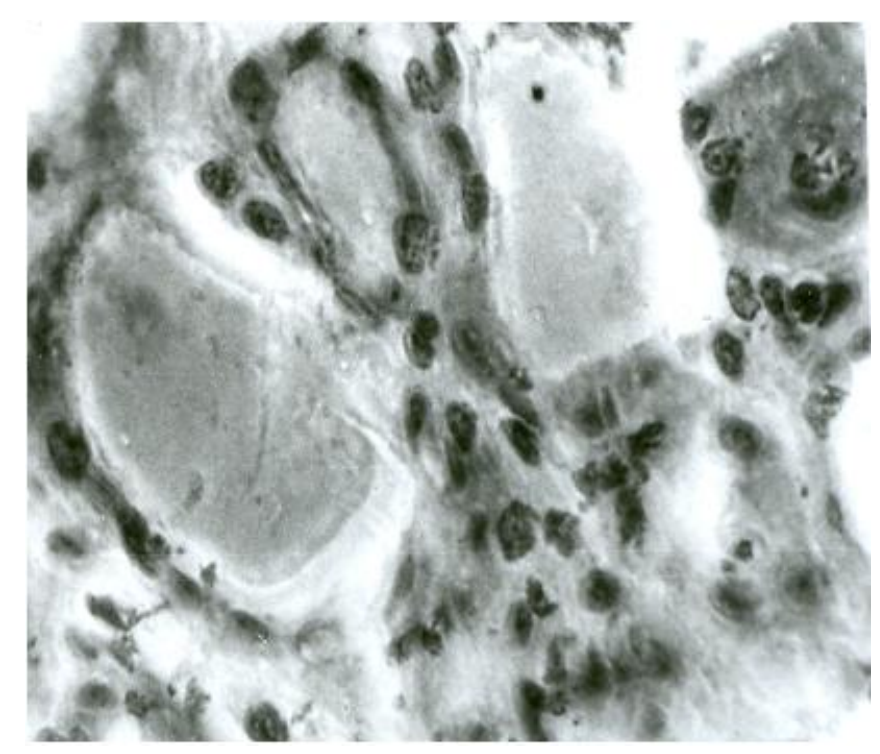

Figure 9. Microphotograph of thyroid gland section from testosterone treated adult male rat showing decreased nuclear diameter and reduced epithelium height. x320 


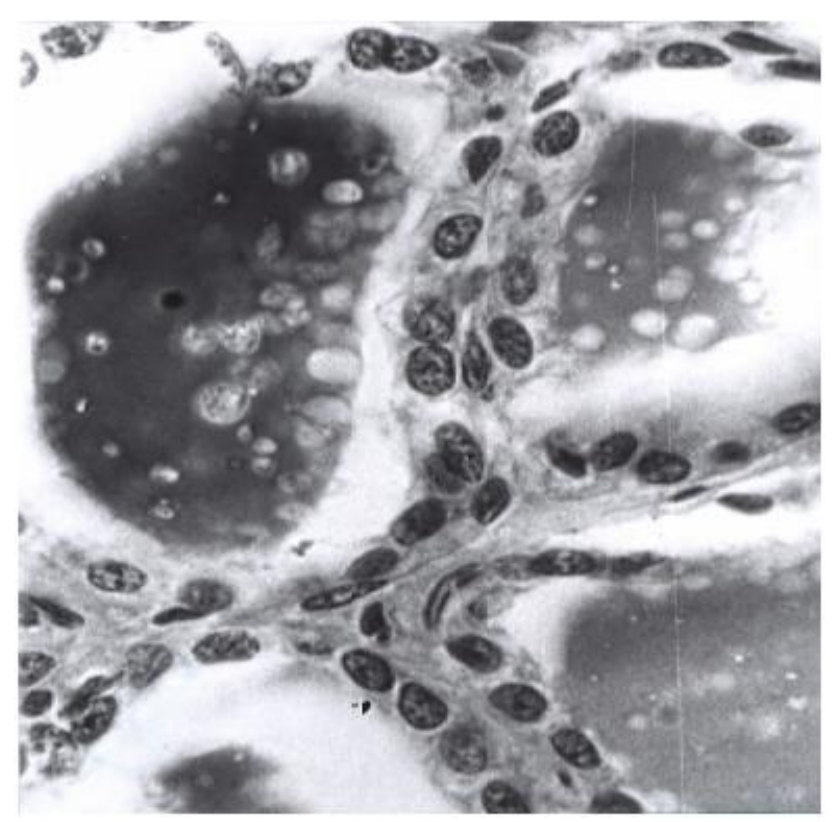

Figure 10. Microphotograph of thyroid gland section from flutamide treated adult male rat showing hyperactive nuclear diameter. $\mathrm{x} 320$

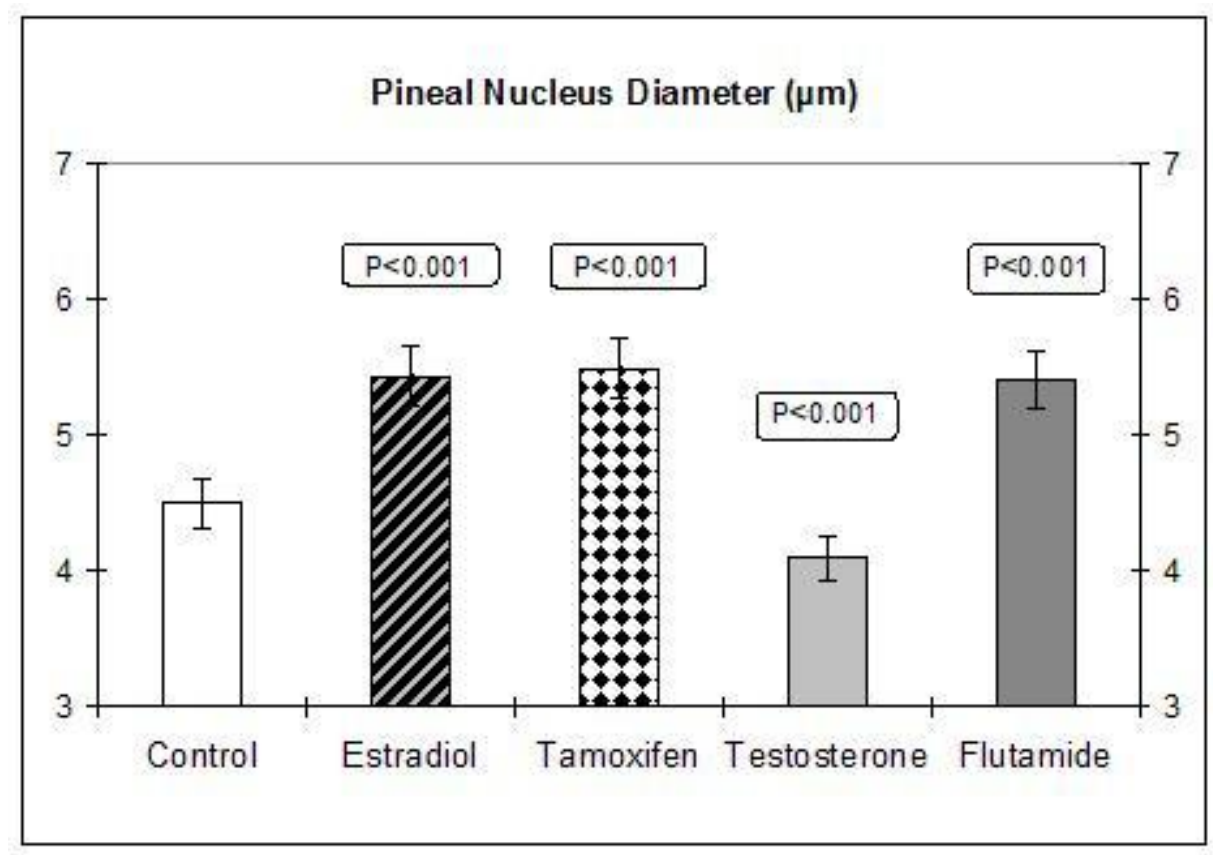

Figure 11. Hitograms showing pinealocyte nuclear diameter $(\mu \mathrm{m})$ following gonadal hormone and antihormone treatment as compred to control value. Estradiol, tamoxifen and flutamide treatment caused a significant increase whereas testosterone treatment showed a decrease in nuclear diameter value as compared to control group. The vertical lines signify the SEM. 


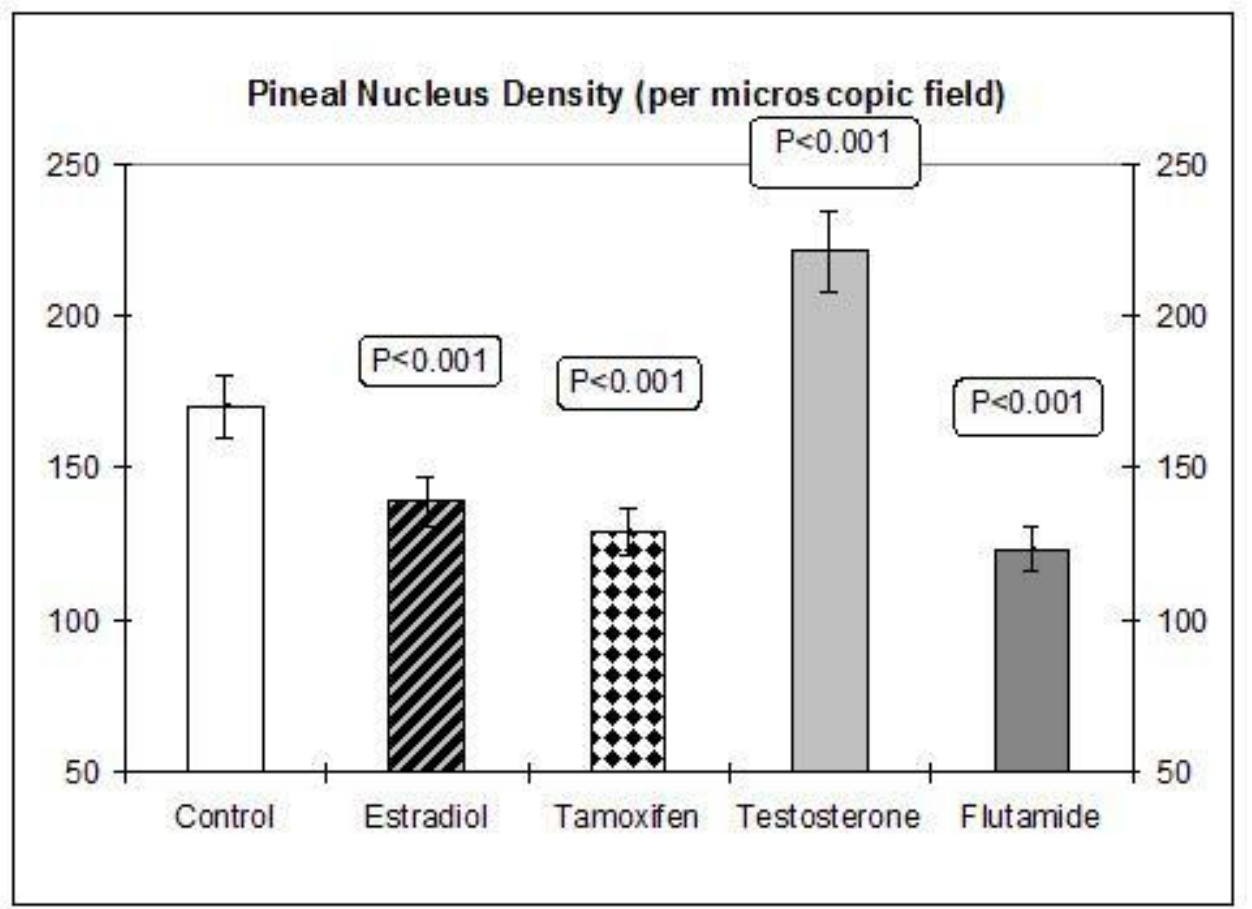

Figure 12. Histogram showing pinealocyte nucleus density per microscopic field following gonadal hormone and antihormone treatment as compared to control value. Estradiol, tamodifen and flutamide treatment caused a significant decrease whereas testosterone treatment showed a significant increase in nucleus density per microscopic field as compared to control group. The vertical lines signify the SEM.

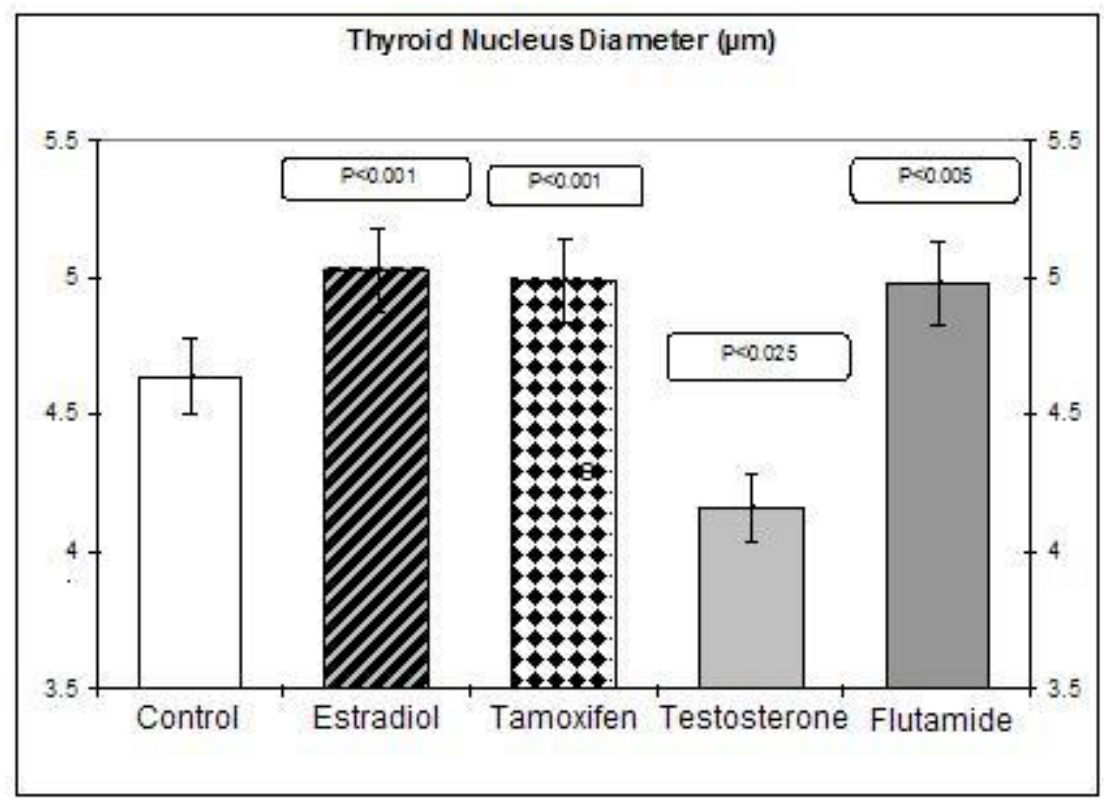

Figure 13. Histogram showing comparison between control and different steroid hormone and antihormone as regard to thyroid nuclear diameter $(\mu \mathrm{m})$ when compared to control value. Estradiol, Tamodifen and Flutamide significantly increased the nuclear diameter $(\mu \mathrm{m})$ whereas Testosterone significantly decreased the nuclear diameter $(\mu \mathrm{m})$ value when compared to control group. The vertical lines signify the SEM. 


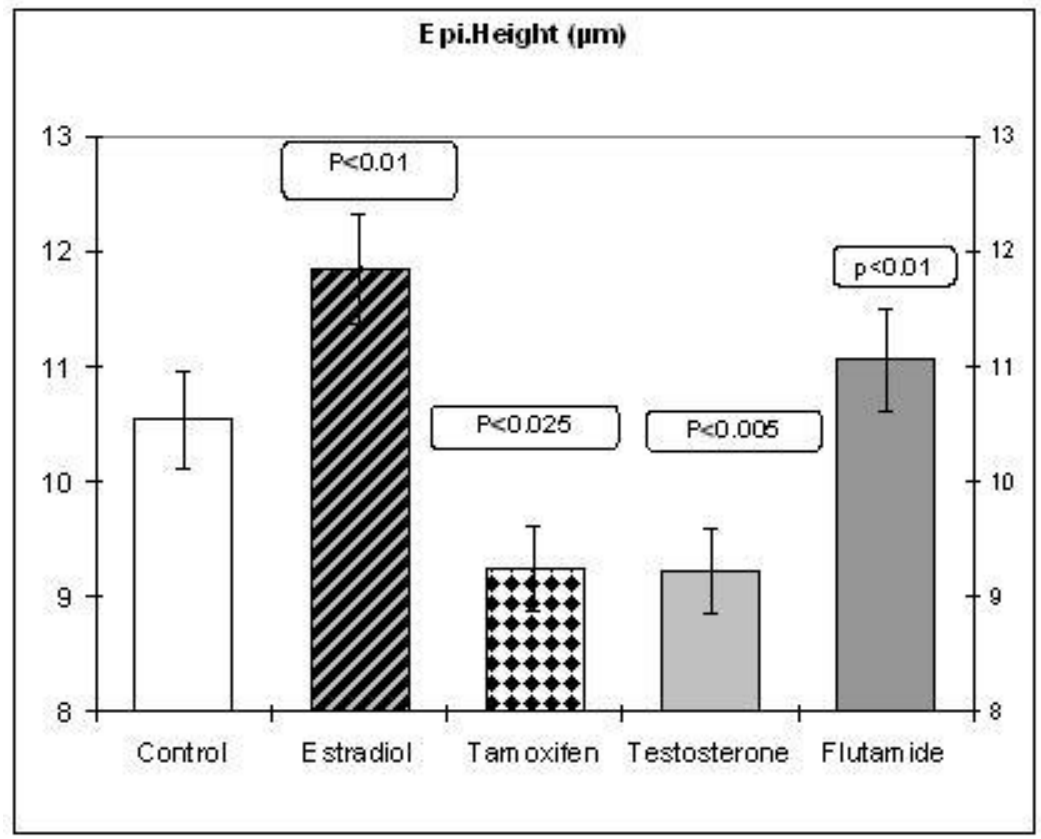

Figure 14. Histogram showing comparison between control and different steroid hormone and antihormone as regard to thyroid epithelium height $(\mu \mathrm{m})$. Estradiol significantly increased the epithelium height, whereas decreased epithelium height was observed in the cases of Tamoxifen and Testosterone. Flutamide failed to produce any significant change in the same when compared to control group. The vertical lines signify the SEM.

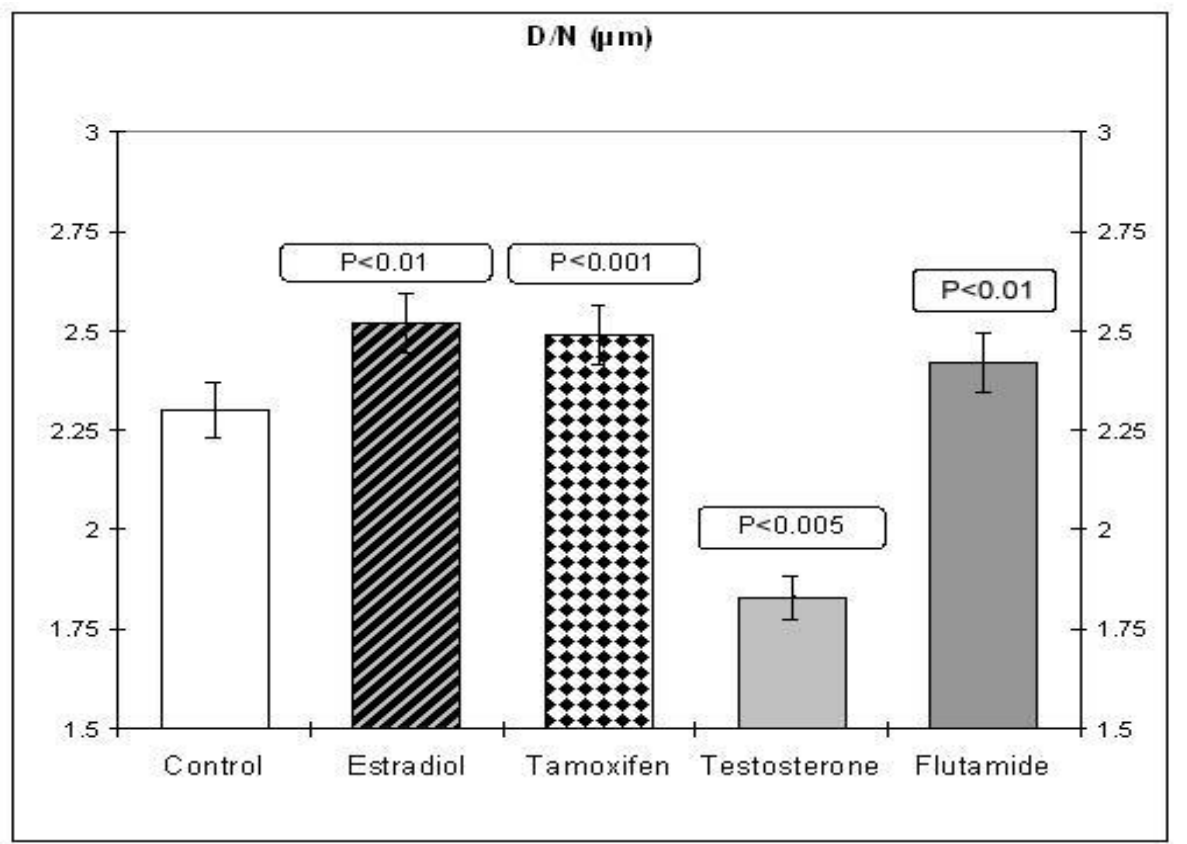

Figure 15. Histogram showing comparison between control and different steroid hormone and antihormone treatment as regard to thyroid $\mathrm{D} / \mathrm{N}(\mu \mathrm{m})$ value when compared to control values. Estradiol, Tamoxifen significantly increased the $\mathrm{D} / \mathrm{N}(\mu \mathrm{m})$ whereas Testosterone significantly decreased the $\mathrm{D} / \mathrm{N}(\mu \mathrm{m})$ and Flutamide failed to produce any significant change in the same when compared to the control group. The vertical lines signify the SEM. 